\title{
Diagnosis of Schistosoma infection in non-human animal hosts: a systematic review and
} meta-analysis

Song Liang ${ }^{1,2}$, Keerati Ponpetch ${ }^{1,2,3}$, Yi-Biao Zhou ${ }^{4}$, Jia-Gang Guo ${ }^{5}$, Berhanu Erko ${ }^{6}$, J. Russell Stothard ${ }^{7}$, M. Hassan Murad ${ }^{8}$, Xiao-Nong Zhou ${ }^{9}$, Fadjar Satrija ${ }^{10}$, Joanne Webster ${ }^{11}$, Justin V. Remais $^{12}$, Juerg Utzinger ${ }^{13,14}$, Amadou Garba ${ }^{5}$

${ }^{1}$ Department of Environmental and Global Health, College of Public Health and Health Professions, University of Florida, Gainesville, FL, United States of America ${ }^{2}$ Emerging Pathogens Institute, University of Florida, Gainesville, FL, United States of America

${ }^{3}$ Sirindhorn College of Public Health Trang, Faculty of Public Health and Allied Health Sciences, Praboromarajchanok Institute, Thailand

${ }^{4}$ School of Public Health, Fudan University, Shanghai, People's Republic of China

${ }^{5}$ Department of Control of Neglected Tropical Diseases, World Health Organization, Geneva,

Switzerland

${ }^{6}$ Aklilu Lemma Institute of Pathobiology, Addis Ababa University, Addis Ababa, Ethiopia

${ }^{7}$ Department of Tropical Disease Biology, Liverpool School of Tropical Medicine, Merseyside, United Kingdom

${ }^{8}$ Division of Preventive Medicine, Department of Internal Medicine, Mayo Clinic College of Medicine, Rochester, MN, United States of America

${ }^{9}$ National Institute of Parasitic Diseases, Chinese Center for Disease Control and Prevention, Shanghai, People's Republic of China

${ }^{10}$ Department of Animal Infectious Diseases and Veterinary Public Health, Faculty of Veterinary Medicine, IPB University, Bogor, Indonesia

${ }^{11}$ School of Public Health, Imperial College, London, United Kingdom

${ }^{12}$ School of Public Health, University of California, Berkeley, Berkeley, CA, United States of America 
${ }^{13}$ Swiss Tropical and Public Health Institute, Basel, Switzerland

${ }^{14}$ University of Basel, Basel, Switzerland

\section{Abstract}

\section{Background}

Reliable and field-applicable diagnosis of schistosome infections in non-human animals is important for surveillance, control, and verification of interruption of human schistosomiasis transmission. This study aimed to summarize uses of available diagnostic techniques through a systematic review and meta-analysis.

\section{Methods and principal findings}

We systematically searched the literature and reports comparing two or more diagnostic tests in non-human animals for schistosome infection. Out of 4,909 articles and reports screened, 18 met our inclusion criteria, four of which were considered in the meta-analysis. A total of 14 techniques (parasitologic, immunologic, and molecular) and nine types of non-human animals were involved in the studies. Notably, four studies compared parasitologic tests (miracidium hatching test $(\mathrm{MHT})$, Kato-Katz (KK), the Danish Bilharziasis Laboratory technique (DBL), and formalin-ethyl acetate sedimentation-digestion (FED-SD)) with quantitative polymerase chain reaction ( $\mathrm{qPCR}$ ), and sensitivity estimates (using $\mathrm{qPCR}$ as the reference) were extracted and included in the meta-analyses, showing significant heterogeneity across studies and animals hosts. The pooled estimate of sensitivity was 0.21 (95\% confidence interval $(\mathrm{Cl}): 0.03-0.48$ ) with FED-SD showing highest sensitivity $(0.89,95 \% \mathrm{Cl}: 0.65-1.00)$.

\section{Conclusions and significance}

Our findings suggest that the parasitologic technique FEA-SD and the molecular technique, qPCR, are the most promising field-applicable techniques for schistosome diagnosis in non- 
human animal hosts. Future studies are needed for validation and standardization of the techniques for real-world field applications.

\section{Author summary}

The diagnosis of schistosome infection in non-human hosts is important for control and elimination of human schistosomiasis. Many diagnostic techniques have been developed and adapted for the detection of schistosome infections in the animal hosts. This study aimed to summarize effectiveness of available diagnostic techniques through a systematic review of the literature and reports comparing two or more diagnostic tests in non-human animals. Overall, 4,909 articles and reports were screened. Nineteen articles met our inclusion criteria and were analyzed in greater detail. A total of 14 techniques (parasitologic, immunologic and molecular) and nine types of non-human animals were involved in the studies. Four studies comparing parasitological tests (miracidium hatching test(MHT), Kato-Katz (KK), the Danish Bilharziasis Laboratory technique (DBL), and formalin-ethyl acetate sedimentation-digestion (FED-SD))) with quantitative polymerase chain reaction (qPCR) were included in the meta-analyses. The findings suggest that the parasitologic technique FEA-SD and molecular techniques, especially qPCR, are promising field-applicable techniques. However, further validation and standardization of the techniques under field condition are much needed. 


\section{Introduction}

Effective disease surveillance is a critical component of health systems, by providing timely information to monitor disease trends, guide interventions, evaluate health outcomes, and set disease control and elimination goals. The transmission of several parasitic diseases involves multiple species of hosts, in addition to humans. Hence, identifying infections in human and non-human hosts through accurate diagnostic tools is central to their surveillance. Schistosomiasis, caused by infection of blood flukes of the genus, Schistosoma, is one such disease and poses health threats to an estimated 800 million people in the tropics and subtropics with more than 250 million people currently infected globally [1-3]]. There are six species that infect humans, among which, Schistosoma mansoni, S. haematobium, and S. japonicum have a wide geographical distribution, are of primary public health concerns, and account for the majority of human disease burdens [4-6]. Furthermore, it is becoming increasingly apparent that humans can be infected, often at very high prevalence levels, with viable hybrids between $S$. haematobium with the livestock schistosome species of $S$. bovis, $S$. curassoni, and S. mattheii across parts of sub-Saharan Africa, as well as rarer cases of human infections with viable hybridized S. bovis with S. currassoni [7-12].

With extensive global efforts to control schistosomiasis over the past 15-20 years, the world has witnessed a significant change in patterns of infection, including remarkable reductions in disease-associated mortality and morbidity that have been achieved in many endemic areas [13-16]. Some successful control programs, including areas that have achieved local elimination of transmission, have been achieved in, for example, certain Caribbean island nations and Brazil in the Americas; Egypt, Morocco, Tunisia, Algeria, and Mauritius in North Africa and the Middle East; Saudi Arabia and Iran in the Persian Gulf; and Japan and the People's of Republic of China in Asia. Such success has encouraged the development of an agenda of schistosomiasis elimination at the global scale $[13-15,17]$. Yet, it has been well recognized that, given the complexity of factors involved in the Schistosoma transmission, 
disease elimination will require integrated efforts targeting multiple components and transmission processes [18-21]. A central element of control efforts is the identification of infection sources for intervention (e.g., finding infected individuals for treatment) through diagnosis of infections. However, as transmission levels are reduced with control efforts, and traditional techniques for diagnosis of schistosome infections butt up against their limits of detection, there is a critical need for sensitive and field-applicable diagnostic procedures for humans [13, 22-24] and possible animal reservoirs of the parasite [25-27]. Such tools would enable effective monitoring and surveillance, as well as verification of elimination of the disease transmission (e.g., no circulation of the pathogen).

Natural infections of non-human animals by the three species of Schistosoma parasites have been reported with varying public health implications based on available evidence. $S$. japonicum is the causative agent of schistosomiasis in Asia, primarily in the People's Republic of China, the Philippines, and parts of Indonesia [18, 28, 29], and is widely recognized as a zoonotic parasite $[4,27,30]$. Over 40 species of wild and domestic mammalian animals can serve as reservoirs of $S$. japonicum [26, 30,31]. Studies in the People's of Republic of China [20, 21, 32-35] and the Philippines [36-39] have revealed that some mammalian reservoirs, in particular buffaloes, have played important roles in the local transmission of schistosomiasis to humans. For example, studies have suggested that bovines may play an important role in sustaining transmission in the lower Yangtze River region of the People's Republic of China [40-43], contributing to from around $60 \%$ of infection sources in the Poyang Lake area [33, 34] to $90 \%$ in Anhui province [44]. Other mammalian hosts, such as horses, pigs, dogs, cats [35, $44]$, and wild rodents [40-43, 45], have been observed with varying levels of infections from field surveys, and their contributions to human infections have received less interest to date compared to bovine hosts.

In hilly and mountainous regions in the southwestern part of the People's Republic of China, longitudinal surveillance data have shown a high correlation between prevalence of 
infection in humans and rodents at the regional $[43,46]$ and bovines at the county scales [unpublished data], and studies have suggested that bovines and rodents were a key factor underlying re-emergence of schistosomiasis transmission in areas previously controlled or locally eliminated $[32,47]$. Field studies in the Philippines have also reported a wide range of $S$. japonicum-infected animal species, with buffaloes and dogs both likely important players in parasite transmission to humans [28, 39, 48-50].

Natural infections of S. mansoni, S. haematobium, and also notably S. haematobium with $S$. bovis hybrids, have been observed in some non-human animals such as primates (e.g., baboons), rodents, and pigs [51-57]. Further, there is also evidence that human S. mansoni is maintained in non-human primates, e.g., in East Africa [57], that shared phylogenetic genotypes are matched, indicative of shared transmission between humans and rodents in West Africa [58]. Yet, the contribution of these animals to the epidemiology of human schistosomiasis transmission remains poorly understood, and further research is needed to estimate the burden of disease attributable to non-human animal circulation [25, 52, 59]. Accurate detection of Schistosoma infection, to the species and ideally strain/genotype level, in animals would provide critical information to guide surveillance and inform control $[7,27,46,58,60]$.

Diagnosis of Schistosoma infection in humans and diagnosis of animal infections rely on techniques that fall in three categories: parasitologic, immunologic, and molecular. Parasitologic techniques typically involve microscopy such as the Kato-Katz (KK) thick smear test and miracidium hatching test (MHT); immunodiagnostic techniques detect species-specific antigens or antibodies; and molecular techniques use parasite DNA for detection. These techniques have been widely used in field settings either separately or in combination, exhibiting varying levels of effectiveness and utility. Similar challenges as those facing the diagnosis in humans arise when seeking to diagnose infections of animal hosts (e.g., insensitivity of the KK and MHT with decreasing infection intensities). Furthermore, diagnosis of infection in animal hosts presents additional challenges, typically associated with sample collection and processing. To assess the 
effectiveness of currently available techniques for Schistosoma diagnosis of non-human animals, we pursued a systematic review and meta-analysis of the literature on diagnosis of animal Schistosoma infections.

\section{Methods}

Search strategy and selection criteria

A systematic literature review was performed with the aim to identify relevant studies, spanning from 1990 to 2020, that examined Schistosoma infections in non-human animal hosts using diagnostic techniques and assess their relative effectiveness in the diagnosis. The PRISMA guidelines [61] for systematic reviews were followed to report this review. We performed searches in the following electronic databases: PubMed, Web of Science, and Science Direct. We also searched the electronic archives of relevant of international agencies, including the World Health Organization (WHO)'s Library Database, the Food and Agriculture Organization (FAO), and World Organization for Animal Health (OIE). Considering that the People's Republic of China is a major S. japonicum endemic country and many relevant studies are published in Chinese, we searched China National Knowledge Infrastructure (CNKI) and Wanfang for Chinese language papers. Books, dissertation, conference abstracts, and unpublished reports were also considered.

The following keywords and combinations were used in the search: "schistosomiasis", "schistosome", "Schistosoma", in combination with "diagnosis", "detection", "infection", "veterinary screening", "parasitological assay", "immunoassay", "molecular assay", and "nonhuman animal", "animal reservoir(s)", and "animal host(s)". Searches included appropriate wildcards and truncations, and the bibliographies of identified documents were hand-searched for additional references. No language restriction was imposed for database searches. Titles of papers retrieved from each database were manually screened first to remove irrelevant 
references. Then abstracts were further screened and the full texts of potentially relevant papers were reviewed. This process was conducted independently by two reviewers (KP and YBZ).

The inclusion and exclusion criteria of articles/studies in the present review are summarized in Figure 1. We considered field-based epidemiologic studies (e.g., cross-sectional) and laboratory-based studies involving diagnosis of Schistosoma infection in non-human animals, as well as relevant veterinary screening (e.g., non-research) and veterinary medicine research. As we are interested in relative effectiveness of diagnostic techniques, only publications, if in the absence of a diagnostic 'gold' standard of infection, reporting the use of at least two diagnostic tools (e.g., parasitologic, or immunodiagnostic, or molecular (e.g., PCRbased) tests, or a combination of them) in the same study were included. Publication reporting, if with confirmed animal infections (as the 'gold' standard, e.g., confirmed artificial infection), two or more diagnostic tests were eligible for inclusion. The study search and selection were performed by two independent reviewers.

\section{Data extraction and types of outcome measures}

Following the identification of eligible studies, relevant information from each reference was extracted and the information included: year of publication, study area (e.g., site and country), study design (e.g., field- or laboratory-based), diagnostic tests, animal species, and sample size (e.g., number of specific animal host examined), outcome measured (e.g., numbers of positive and negative tests), and entered into a standardized Excel sheet by authors independently. The primary outcome is proportion of test positive (test positive/examined $\mathrm{x}$ $100 \%$ ) by diagnosis through a specific test (e.g., parasitologic, immunologic, or molecular tests). For studies with comparable information (involving consistent comparisons across diagnostic techniques, e.g., a study comparing a few parasitologic techniques with a molecular technique, qPCR), they were included in the assessment of agreement test and relative sensitivity of diagnosis, cross-tabulated information was extracted. 


\section{Statistical analysis}

Due to limited availability of data using comparable tests, statistical analyses were limited to a subset of comparisons between parasitologic assays and immunoassays (limited to MHT vs. enzyme-linked immunosorbent assay (ELISA), the colloidal gold immunochromatography assay (GICA), the dot immunogold filtration assay (DIGFA), and dye dipstick immunoassay (DDIA), and molecular assays and parasitological assays (limited to qPCR vs. MHT, KK, the Danish Bilharziasis Laboratory (DBL), and formalin-ethyl acetate sedimentation technique(FEA-SD), see Table 1 for detail). Cohen's Kappa estimate was used to assess the degree of agreement between two tests across the studies with comparable information [62]. For studies with comparable data on tests, which were limited to four parasitologic techniques - MHT, KK, DBL, and FEA-SD), sensitivity was estimated using qPCR result as the reference given the availability of comparable data and qPCR being reported to be a highly sensitive technique in the detection of schistosome infection in animals [63-66]. The Kappa and sensitivity summary statistics across comparisons were estimated using generic inverse variance weighting method. Heterogeneity across comparisons was tested using $P^{2}$ statistic (e.g., inconsistency or variability in effect estimates across studies) .

Pooled estimates of sensitivity of selected diagnostic tests were analyzed in a metaanalysis using a random-effects model. Due to heterogeneity of diagnostic tests across the included studies and limited studies with comparable information, we restrict our analysis to the studies with comparable information for the meta-analysis. The meta-analysis was performed in STATA Version 10 [67].

\section{Results}

Search results 
The search process and results are shown in Figure 1. The search terms returned 4,909 records from all databases, reducing to 712 records after the title screening and duplicate removal. Through further examination by removing articles on review, development of diagnostic assays (e.g., not for field and/or laboratory applications), non-human Schistosoma species, 62 studies were identified for full-text review. Of these, 43 articles contained insufficient information or only one diagnostic test and were excluded from the review. The remaining 19 studies (Table 1) were included for qualitative analysis in this review and four of them were included in the meta-analysis [45, 50, 66, 68-72].

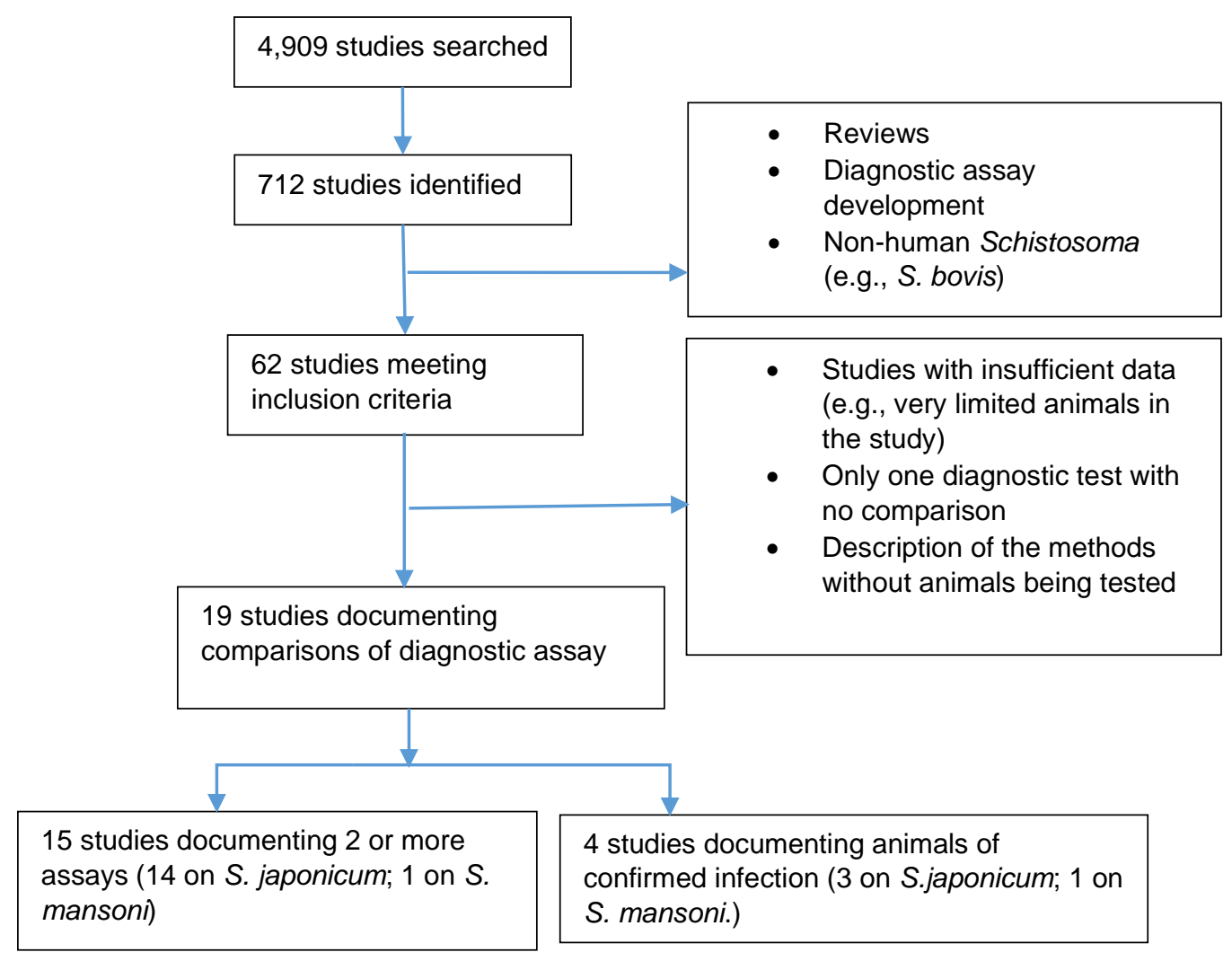

Figure 1. Flowchart showing inclusion and exclusion of studies on diagnosis of Schistosoma infections in non-human animals and search results. Note that, for the four studies with confirmed infections prior to diagnostic testing (on lower right box), more than two diagnostic techniques were also examined in each study. 
General characteristics

This review identified 19 studies published between 1993 and 2020; key characteristics of the included studies are summarized in Table 1. Among the included studies, 15 were fieldbased (e.g., cross-sectional surveys of non-human animals), three were based on experimentally infected animals, and one involved both. Seventeen of them were based on $S$. japonicum, involving a range of hosts including domestic animals (e.g., buffalo, cattle, dog, goat, and pig), laboratory animals (e.g., mouse and rabbit), and wild animals (e.g., rodent) in the People's Republic of China and the Philippines, while the other two papers examined $S$. mansoni in chimpanzee and rodents in Uganda and Brazil, respectively (Table 1).

All studies involved the use of two or more diagnostic techniques in the three categories of Diagnostic techniques-parasitologic $(n=4)$, immunologic $(n=8)$, and molecular techniques $(n=2)$. Key characteristics of these techniques are summarized in Box 1. Among the 19 studies, two studies used all three types of techniques, five studies used both parasitologic and molecular techniques, five used both parasitologic and immunologic techniques, two studies used both immunologic and molecular techniques, and five studies used two immunologic techniques (Table 1). Sample sizes varied substantially across the studies and different animal hosts, with the majority of study animals being buffalo and cattle, accounting for $87.7 \%(8,145 / 9,284)$ of the total number of animals examined. Thirty-nine non-human primate (all chimpanzees) were examined for S. mansoni in Uganda [73]. 
As diagnosis of Schistosoma infections in humans, development and utilization of diagnostic tools for Schistosoma infections in non-human animals are also important for surveillance and control of the disease involving zoonotic transmission. The development and use of diagnostic tools for animal infections have, to some extent, paralleled those of diagnosis of human Schistosoma infections. Many techniques have been developed and/or adapted (e.g., from diagnostic techniques of human infection) and these techniques can be broadly grouped to three major categories - parasitologic, immunologic, and molecular techniques. The techniques used in the studies included in this review are summarized below.

\section{Parasitological techniques}

As for the diagnosis of human schistosome infection, detection of excreted schistosome eggs from fecal samples of animal hosts is a customary method, which is direct and specific. Four techniques were used in the 13 studies - the KK thick smear test, the MHT, the DBL technique, and the FEA-SD technique.

The Kato-Katz technique (KK). The KK is the standard method recommended by WHO for both qualitative and quantitative diagnosis of intestinal schistosomiasis (e.g., S. japonicum and $S$. mansoni) and the most commonly used method in the field for diagnosis of human infections with these species [23, 74]. The KK was also adapted for detection of schistosome infection in non-human animal hosts. Briefly, fresh, homogenized stool sample is pressed through approximately 60-105 $\mu \mathrm{m}$ mesh and filled in a standard volume template designed to contain approximately $41.7 \mathrm{mg}$ of stool on a microscopic slide. The resulting sample on the slide is then covered with glycerin/methylene blue-soaked cellophane (to clear the fecal samples) and pressed to spread the stool evenly on the slide which is then checked under a microscope. Two to three slides for each stool sample are prepared and screened by experienced microscopists with the egg count is expressed typically as the number of eggs per gram of stool (EPG) through multiplication with a correction factor (e.g., 8 or 12 depending on the number of slides). 
Miracidium hatching test (MHT). The MHT is another commonly used method for detection of schistosome (in particular S. japonicum) infections in humans and animals. The technique checks for live miracidia through egg hatching to detect infection. Briefly, homogenized stool samples, usually $\sim 50 \mathrm{~g}$, are sieved through 1-2 layers (with slight variations over different studies/applications) of mesh, the sediment is then collected and placed to an Erlenmeyer flask filled with fresh, unchlorinated water (with $\mathrm{pH}$ around 7.0), and is subjected to artificial or natural light at room temperature controlled in the range of $25^{\circ} \mathrm{C}$ to $30^{\circ} \mathrm{C}$. The neck of the flask is then examined at intervals (typically $1,4,8,12$, and 12 hours) to detect the presence of miracidia [75]. Slight modifications, depending on field and laboratory logistics, have been made across field applications [26, 32, 35, 45, 50].

The Danish Bilharziasis Laboratory (DBL) technique. The DBL technique was initially developed for the evaluation of $S$. japonicum eggs in pig feces. The basic procedure involves filtration, sedimentation and centrifugation [76]. Briefly, $5 \mathrm{~g}$ of feces taken from homogenized specimens is mixed with $100 \mathrm{ml}$ of $1.2 \%$ saline, agitated for $5-10 \mathrm{~min}$, and gone through 3 layers of sieves at 400,100 , and $45 \mu \mathrm{m}$ mesh size, respectively. The residue materials remaining on the $45 \mu \mathrm{m}$ mesh sieve is then removed to a sedimentation flask, filled with saline to allow sedimentation in the dark. The sediment was then centrifuged and re-suspended to obtain a final volume of 2.25 $\mathrm{ml}$. After thoroughly mixing, $150 \mu \mathrm{l}$ of the solution is then removed to a $1 \mathrm{ml}$ microscope chamber slide mixed with $850 \mu \mathrm{l}$ of saline. Three chamber slides are then examined under a microscope to count the number of schistome eggs to obtain the intensity measure, the total number of EPG [36, 76].

Formalin-ethyl acetate sedimentation-digestion (FEA-SD) technique. A procedure has been developed for quantification of $S$. japonicum eggs from bovine feces. The basic procedure involves filtration, sedimentation, potassium hydroxide digestion, centrifugation, and then microscopy [77]. Briefly, $50 \mathrm{~g}$ of homogenized fecal sample is sieved through 40-60 copper mesh ( $234-380 \mu \mathrm{m})$ sieve and subsequently a 260 copper mesh $(61 \mu \mathrm{m})$ sieve. The sediment 
on the second layer mesh is then washed into a conical flask, mixed through shaking, and sedimented for $30 \mathrm{~min}$. The sediment is re-suspended in $10 \%(\mathrm{v} / \mathrm{v})$ formalin and natural sedimentation repeated twice. The resulting suspension is then subjected to two rounds of centrifugations and digestion using potassium hydroxide, and further centrifugation before microscopy. The detailed operation procedures are reported by $\mathrm{Xu}$ et al. [77].

\section{Immunodiagnostic techniques}

Like diagnosis of human schistosome infections, a range of immunodiagnostic techniques have been developed targeted on anti-schistosome antibodies or schistosome antigens present in serum/urine for infection detection of non-human animals. In this review, eight immunodiagnostic techniques were reported in the included studies, including ELISA, circumoval precipitin test (COPT), the colloidal gold immunochromatography assay (GICA), indirect hemagglutination assay (IHA), DIGFA, the dipstick dye immunoassay (DDIA), polyacetal polystyrene immunization microspheres (PAPS), and circulating cathodic antigen (CCA). Enzyme-linked immunosorbent assay (ELISA) There are a few ELISA-based serologic tests developed for detection of animal schistosome infection. Among them, the ELISA test that uses soluble egg antigen (SEA) as the target is the most widely used technique for a range of hosts, such as buffalo, goat, mice, rabbit, rodents, and sheep [78-82]. Some recombinant proteinsbased ELISA (e.g., SjTPx-1) tests were developed and tested in buffalo [78]. Indirect hemagglutination assay (IHA). IHA is one of widely used alternative test to detect human and animal infections with Schistosoma $[75,79,83]$. The test uses erythrocytes coated with schistosome adult worm antigen and has been widely used in diagnosis of $S$. japonicum infections in buffalo and cattle in the People's Republic of China.

Circumoval precipitin test (COPT). The test is a simple and inexpensive immunodiagnostic test used to detect serum antibodies to schistosome and developed for diagnosis of schistosome in 
humans $[84,85]$. The test was adapted for detection of schistosome infection in animals such as buffaloes [78].

Dipstick dye immunoassay (DDIA). DDIA was developed for detection of antibodies against $S$. japonicum in humans using SEA labelled with a colloidal dye [86]. The technique has subsequently extended to diagnosis of animals [87].

The colloidal gold immunochromatography assay (GICA). GICA combines with the doubleantigen sandwich assay and has been used for detection of antibody caused by schistosome infection. Most current applications focus on S. japonicum in a wide range of animal hosts [70, $79,81]$

The dot immunogold filtration assay (DIGFA). DIGFA is a rapid technique, based on an immune labelling technique developed in the late 1980s, for detection of antibodies to infectious agents. The technique was developed for detection of anti-S. japonicum antibody in humans in the People's Republic of China [88] and then extended to diagnosis of S. japonicum infection in cattle $[69,82]$.

Polyaldehyde polystyrene immunization microspheres (PAPS). This technique for schistosome detection was developed in late 1980s in the People's Republic of China. It uses immunospheres of polyaldehyde polystyrene to link with special antigenic ligates (SEA of $S$. japonicum) and was used for diagnosis of S. japonicum in cattle in the People's Republic of China $[71,89]$.

Circulating cathodic antigen (CCA) assay. This technique detects the presence of schistosome CCA released from adult worms and is a widely used technique for all three species of Schistosoma of main public health concern. In this review, CCA assay was used (in comparative test) only in one study on S. mansoni [73].

\section{Molecular techniques}


PCR-based techniques. The techniques detect (e.g., qualitative) and quantify (e.g., both qualitative and quantitative) Schistosoma-specific DNA from samples (e.g., fecal or urine depending on species). Extensive studies across different Schistosoma species claim very high sensitivities and specificities. Both qualitative (classic PCR) and quantitative PCR (qPCR) have been explored for S. japonicum and S. mansoni in animals and evaluated in both laboratory and field settings $[45,66,72,73,78,80,81,90]$.

\section{Comparisons of results from different diagnostic techniques}

The 19 studies included in the review used 14 diagnostic tests- 13 studies used one or more parasitologic assays, 14 studies used one or more immunologic assays, and nine studies used either PCR, or qPCR, or both (Table 1). Given the availability of comparable information within and across studies, the following comparisons and analysis were conducted.

Parasitologic, immunodiagnostic, and molecular techniques. Two studies (both on S. mansoni) used all three types of diagnostic techniques. In the first study that examined intestinal schistosome infections in wild-born chimpanzees in Uganda, Standley et al. [73] reported results of different diagnostic tests with substantial variations in outcome measures - proportions of test positive were $5.3 \%, 93.5 \%, 50.0 \%$, and $54.2 \%$ by duplicate KK thick smears, ELISA, CCA, and qPCR tests, respectively. The second study used the KK, ELISA, and PCR tests on experimental rodents, yielding results of proportions of test positive at $68 \%, 100 \%$, and $79 \%$, respectively [90].

$\underline{\text { Parasitologic and immunodiagnostic techniques. Five studies (all pertaining to S. japonicum) }}$ used the two types of diagnostic techniques. For parasitologic tests, all studies used MHT, and for immunologic tests, six of them (ELISA, DDIA, IHA, PAPS, DIGFA, and GIGA) were involved in the studies. Jiang et al. [68] used MHT and ELISA to examine cattle in an endemic area of Hunan, the People's Republic of China and reported $13.4 \%$ and $18.5 \%$ of proportion of positive 
by the two tests, respectively. Sun and Zhang [71] compared MHT and PAPS tests in cattle in a highly endemic area of Hubei province, where both tests showed $100 \%$ prevalence of schistosome infections among the cattle. Peng et al. [70] compared the use of MHT, GICA, and IHA in goats, buffalo, and cattle, showing significant variations in positive detected by MHT (in the range of $3.1 \%$ to $5.1 \%$ ) and GICA/IHA (in the range of $7.4 \%$ to $10.2 \%$ ) Lu et al. [69] examined the performance of MHT, ELISA, and DIGFA, all showing 100\% proportion of positive in the cattle in a field study in Zhejiang province, People's Republic of China.

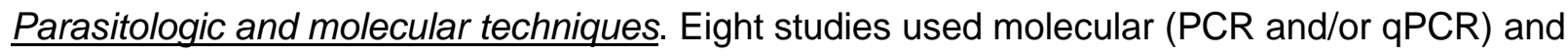
parasitologic (KK, MHT, DBL, and FEA-SD) techniques (Table 1). In the study on buffalo in the Philippines, Wu et al. [66] compared qPCR vs. KK, MHT, and DBL, and found substantial variations in schistosome detection associated with the different tests - the three parasitologic assays reported proportions of test positive from 0 to $3.7 \%$ while qPCR test indicated about $51.5 \%$ proportion of test positive. In another study pertaining to buffalo also conducted in the Philippines, Gordon et al. [72] evaluated the performance of KK, MHT, a newly developed parasitologic test, FEA-SD, and qPCR, showing that $25.0 \%$ and $19.1 \%$ proportions of test positive were identified by KK and MHT, while the FEA-SD and qPCR picked up $93.2 \%$ and 90.9\% of the test positives, respectively. Fung et al. [63] compared MHT and PCR in the detection of schistosome infection in bovine, which gave the same result (62.5\% test positive) There were two studies on S. mansoni conducted in Brazil and Uganda, respectively. The Brazilian study used KK and PCR tests on rodents and found $65 \%(\mathrm{KK})$ and $75 \%$ (PCR) proportions of test positive, respectively [90], while the study on chimpanzee in Uganda reported test positive at $5.3 \%$ by KK, $1.1 \%$ by MHT, $93.5 \%$ by ELISA, $50.0 \%$ by PCR, and $54.2 \%$ by qPCR, respectively [73].

Given the availability of comparable data, four studies were included in meta-analysis of sensitivity analysis of the four parasitological techniques, using qPCR a reference test. The four 
studies, all pertaining to $S$. japonicum, used one or two of parasitological tests $-\mathrm{KK}, \mathrm{MHT}, \mathrm{DBL}$, or FEA-SD - and qPCR. Estimates of sensitivity associated with each of the four parasitological assays were included in the meta-analysis which showed substantial variations over parasitological tests across different hosts. The pooled estimates of sensitivity for MHT, KK, FED-SD, and DBL tests were 0.01 (95\% Cl: 0-0.05), 0.06 (95\% Cl: 0-0.21), 0.89 (95\% Cl: 0.651.0), and 0.06 (95\% Cl: $0.02-0.15)$, respectively, with the overall estimate of $0.21(95 \% \mathrm{Cl}$ : 0.03-0.48) (Figure 2). 
Table 1. Key characteristics of identified studies on diagnosis of schistosome infections in non-human animals

\begin{tabular}{|c|c|c|c|c|c|c|c|c|}
\hline Species & Location & Study & Hosts & $\begin{array}{c}\text { Sample } \\
\text { size }\end{array}$ & $\begin{array}{c}\text { Parasitologic } \\
\text { assay }\end{array}$ & Immunoassay & $\begin{array}{c}\text { Molecular } \\
\text { assay }\end{array}$ & Reference \\
\hline S.j. & $\begin{array}{l}\text { Dongting } \\
\text { Lake, } \\
\text { China }\end{array}$ & Field & $\begin{array}{l}\text { Rodent, } \\
\text { dog, goat, } \\
\text { buffalo, } \\
\text { cattle }\end{array}$ & $\begin{array}{c}76,52,145 \\
10,10\end{array}$ & $\mathrm{KK}, \mathrm{MHT}$ & & $\begin{array}{l}\text { qPCR, } \\
\text { ddPCR }\end{array}$ & [45] \\
\hline S.j. & China & $\begin{array}{l}\text { Exp + } \\
\text { Field }\end{array}$ & $\begin{array}{l}\text { Mice, rabbit, } \\
\text { buffalo, goat }\end{array}$ & $\begin{array}{c}70,50,132 \\
117\end{array}$ & & ELISA, GICA & & [81] \\
\hline S.j. & $\begin{array}{c}\text { Leyte, } \\
\text { Philippines }\end{array}$ & Field & $\begin{array}{l}\text { Cattle, } \\
\text { carabao }\end{array}$ & 48,105 & FEA-SD & & qPCR & [72] \\
\hline S.j. & $\begin{array}{c}\text { Samar, } \\
\text { Philippines }\end{array}$ & Field & Carabao & 44 & $\mathrm{KK}, \mathrm{MHT}$ & & $\begin{array}{l}\text { PCR, } \\
\text { qPCR }\end{array}$ & [50] \\
\hline S.j. & $\begin{array}{c}\text { Sichuan, } \\
\text { China }\end{array}$ & Field & Bovine & 8 & MHT & & PCR & [63] \\
\hline S.j. & $\begin{array}{l}\text { Cagayan, } \\
\text { Philippines }\end{array}$ & Field & Buffalo & 50 & & ELISA, COPT & PCR & [78] \\
\hline S.m. & $\begin{array}{l}\text { Lake } \\
\text { Victoria, } \\
\text { Uganda }\end{array}$ & Field & Chimpanzee & 39 & KK, MHT & ELISA & qPCR & [73] \\
\hline
\end{tabular}




\begin{tabular}{|c|c|c|c|c|c|c|c|c|}
\hline S.m. & Brazil & Exp & Rodent & 23 & $\mathrm{KK}$ & ELISA & PCR & [90] \\
\hline S.j. & $\begin{array}{l}\text { Hubei, } \\
\text { China }\end{array}$ & Field & Buffalo & 178 & & ELISA & PCR & [80] \\
\hline S.j. & $\begin{array}{c}\text { Leyte, } \\
\text { Philippines }\end{array}$ & Field & Buffalo & 81 & $\mathrm{KK}, \mathrm{MHT}, \mathrm{DBL}$ & & qPCR & [66] \\
\hline S.j. & $\begin{array}{l}\text { Hunan, } \\
\text { China }\end{array}$ & Field & $\begin{array}{l}\text { Goat, } \\
\text { buffalo, } \\
\text { cattle }\end{array}$ & $\begin{array}{c}314,197 \\
162\end{array}$ & MHT & GICA, IHA & & [70] \\
\hline S.j. & $\begin{array}{c}\text { Zhejiang, } \\
\text { China }\end{array}$ & Exp & Cattle & 110 & & ELISA, DIGFA & & [82] \\
\hline S.j. & China & Exp & Sheep & 107 & & ELISA, GICA & & [79] \\
\hline S.j. & $\begin{array}{c}\text { Zhejiang, } \\
\text { China }\end{array}$ & Field & Cattle & 139,140 & MHT & $\begin{array}{c}\text { ELISA, T- } \\
\text { DIGFA }\end{array}$ & & [69] \\
\hline S.j. & $\begin{array}{l}\text { Hunan, } \\
\text { China }\end{array}$ & Field & Cattle & 110 & MHT & ELISA & & [68] \\
\hline S.j. & $\begin{array}{l}\text { Hunan, } \\
\text { China }\end{array}$ & Field & Cattle, pig & 33,50 & MHT & DDIA & & [87] \\
\hline S.j. & $\begin{array}{l}\text { Jiangxi, } \\
\text { China }\end{array}$ & Field & Cattle & 2277 & & IHA, PAPS & & [89] \\
\hline S.j. & Zhejiang, & Field & Cattle, & 94,96 & & ELISA, IHA & & [91] \\
\hline
\end{tabular}




\begin{tabular}{|c|c|c|c|c|c|c|c|}
\hline & China & & rabbit & & & & \\
\hline S.j. & $\begin{array}{l}\text { Hubei, } \\
\text { China }\end{array}$ & Field & Cattle & 4217 & MHT & PAPS & [71] \\
\hline
\end{tabular}

Study, field - field-based epidemiologic study (primarily cross-sectional studies); Exp - experiment-based studies; cases (animals experimentally infected) and controls (not infected) were included

Parasitologic assay, KK- Kato-Katz technique; MHT - miracidium hatching test; DBL - the Danish Bilharziasis Laboratory technique; FEA-SD - the formalin-ethyl acetate sedimentation technique.

Immunoassay, ELISA - enzyme-linked immunosorbent assay; GIGA - gold immunochromatography assay; COPT - circumoval precipitin test; DDIA dipstick dye immunoassay; IHA - indirect hemagglutination; PAPS - polyacetal polystyrene immunization microspheres; DIGFA -dot immunogold filtration assay; CCA- circulating cathodic antigen

Molecular assay, PCR - polymerase chain reaction; $\mathrm{QPCR}$ - real-time (or quantitative) polymerase chain reaction 
Table 2: Result of different diagnostic techniques used in the included studies (proportion of test positive, and numbers of tested and test positive)

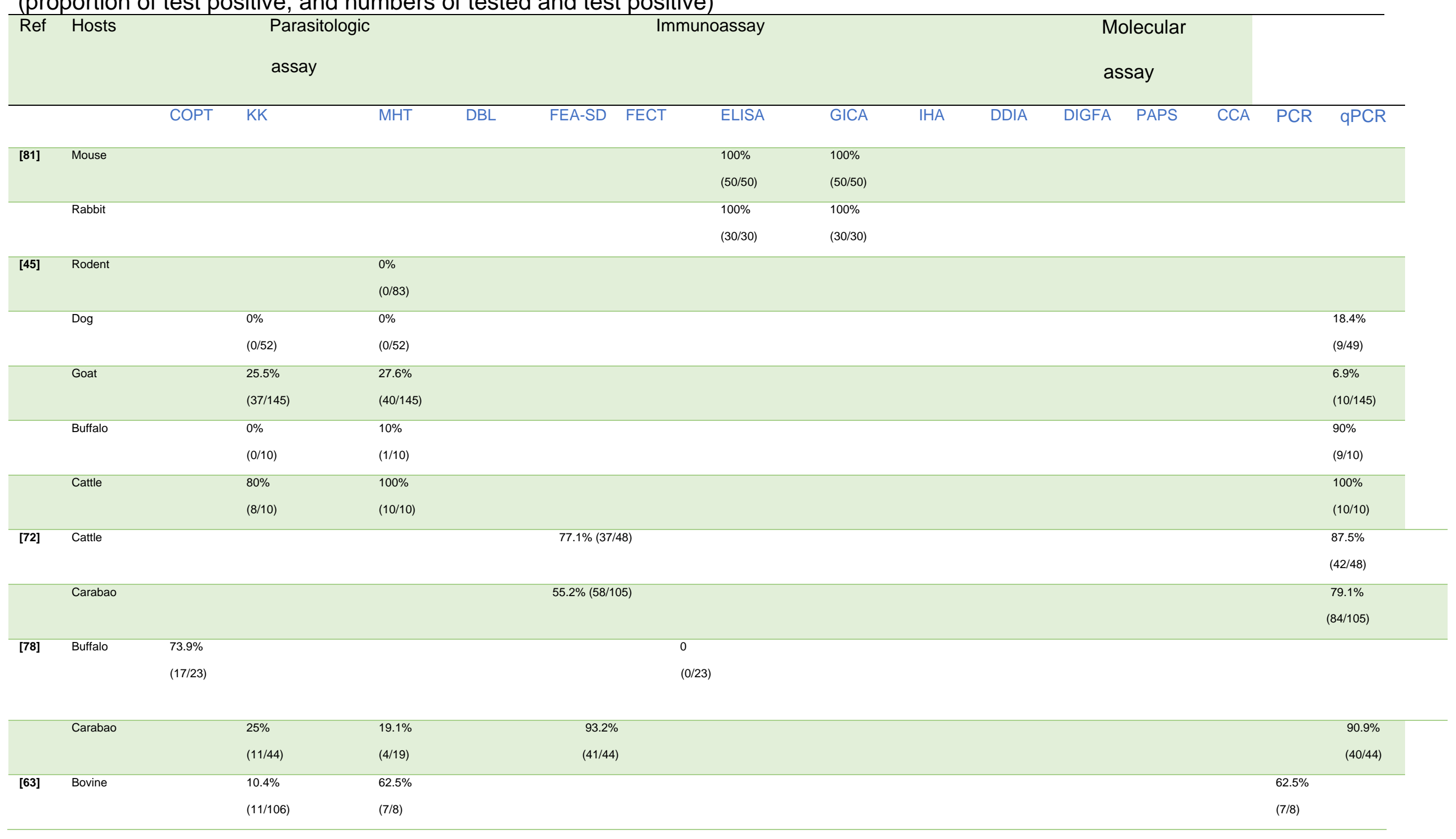




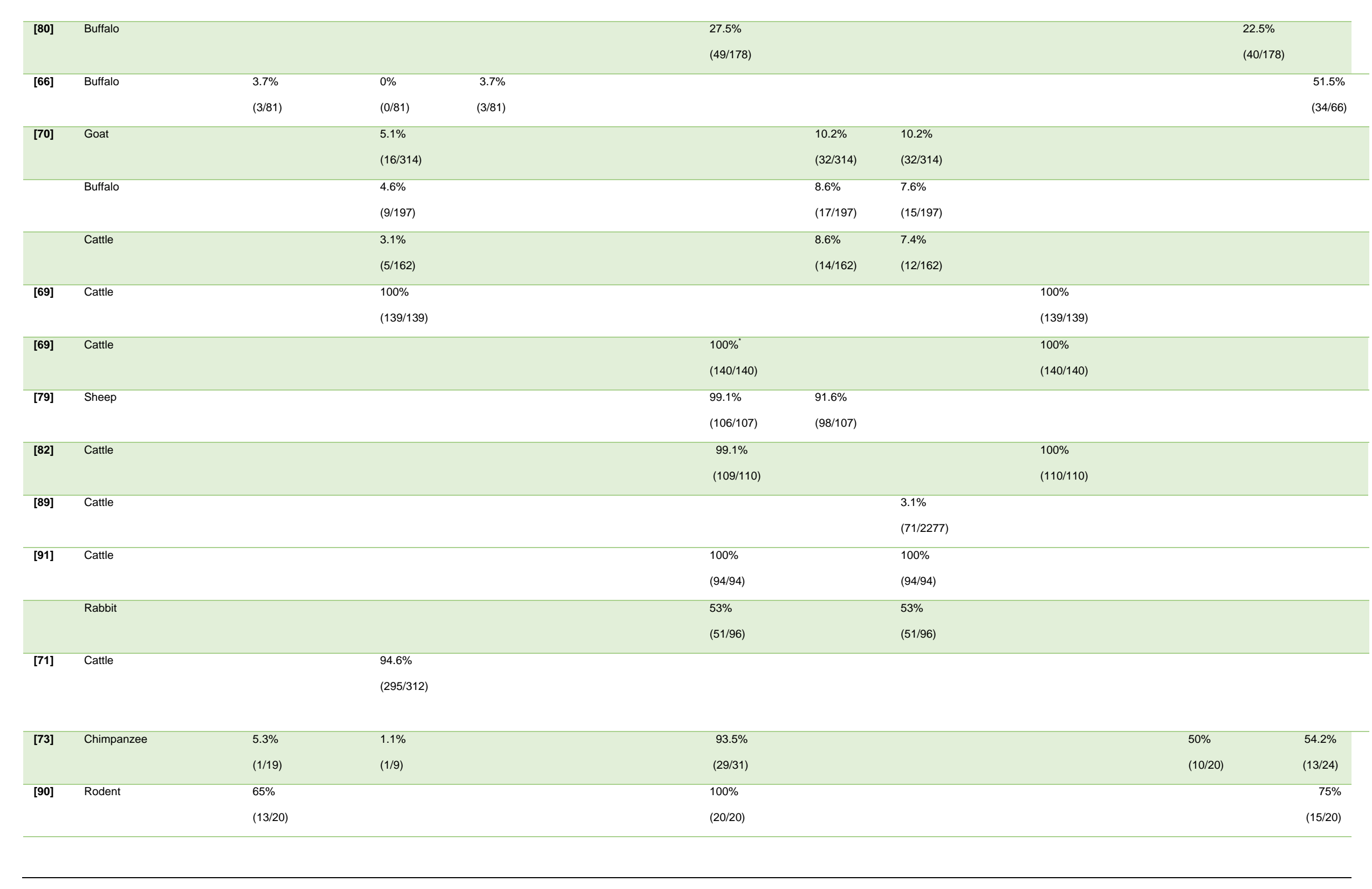




\section{Discussion}

Over the past 30-40 years, many diagnostic techniques have been developed and adapted for the detection of Schistosoma infection in non-human hosts. Some of these techniques have been used widely, while others have had limited application in practice. Establishing optimal techniques for field application is challenging, as the 'effectiveness' of a diagnostic test depends on a wide array of factors, such as parasite biology, transmission levels of the parasite, species of animal hosts involved, and local infrastructure and capacity, among others. Here, by means of a systematic review, 19 studies were identified that employed 14 diagnostic techniques, classified as parasitologic, immunologic, or molecular (Table 1). Consistent, quantitative comparisons could not be undertaken for many of the reported techniques for lack of comparable published data, particularly for immunodiagnostic assays. Quantitative comparisons were performed between four parasitologic assays and qPCR for a subset of studies. While limited, these comparisons yielded valuable information and identified important, remaining knowledge gaps.

As for diagnosis of human schistosome infections, parasitological tests, in particular direct microscopic techniques such as $\mathrm{KK}$ and $\mathrm{MHT}$, are widely used for the diagnosis of zoonotic schistosome infections. Important limitations of these techniques are widely recognized. First, their test sensitivities decease with the declining infection intensity or level of transmission $[13,23,26,35]$. Second, for diagnosis of schistosome infection in animals, in particular large animals such as buffalo and cattle, which play an important role in schistosomiasis transmission to humans in parts of East Asia, the MHT was preferred over the KK due to the use of much larger size of fecal samples, yieldinga better performance of diagnosis based on extensive fieldwork reported in the People's Republic of China [32, 35, 63, 77]. However, it should be noted that MHT results were highly sensitive to $\mathrm{pH}$, temperature, and quality of the water used in the hatching assays and if not controlled well, could significantly impact test results [77]. A recent study in West Africa on the detection of S. bovis and S. curassoni, as well as hybrids in 
livestock (cattle, goat, and sheep) using KK and MHT techniques (and using abattoir data to estimate sensitivities of the tests used) also suggested that overall MHT tests had significantly higher sensitivities than KK for cattle, although there were significant differences in the performance of the MHT depending on infecting schistosome species [8]. In contrast, there were no significant differences in estimates of test sensitivity by parasite species in sheep and goats, nor between proportions testing positive by each test [8].

Among the four parasitological techniques, the FEA-SD, a recently developed microscopic test, has shown high sensitivity and specificity [77]. The procedure involved in the FEA-SD technique is relatively straightforward and easy to implement under field conditions. This technique is an important improvement, overcoming the limitations of classic parasitologic techniques in detecting schistosome eggs in animals - for example, the feces of large animals (e.g., bovine) typically comprise large masses containing cellulosic fiber and abundant debris that obscure egg detection under microscope using the classic KK test. The FEA-SD procedure can clear large proportions of the debris, enabling more efficient observation [77]. Using the qPCR as the reference test, the sensitivity of each of the four tests was estimated for the four eligible studies, and meta-analysis shows that the FEA-SD has the highest pooled estimate of sensitivity, $0.89(95 \% \mathrm{Cl}: 0.61-1.00)$ in contrast with much lower estimates for the other three parasitological assays (Figure 2). The FEA-SD provides a very similar level of diagnostic accuracy as qPCR. Given the much lower cost of diagnosis using FEA-SD compared to that of qPCR, the newly developed parasitologic technique has the potential as an affordable test for detection of schistosome infection in animals. It should be noted that, in the study by Van Dorssen and colleagues [45], the performance of both $\mathrm{KK}$ and MHT in the diagnosis of goats was better than that of qPCR, resulting in high sensitivity of both tests using qPCR as a reference. The low performance of qPCR in comparison with $\mathrm{KK}$ and MHT was unexpected and the authors later identified that this might be due to presence of inhibitors in the goat stools [45]. Hence the information on goats was not included in the meta-analysis. It should also be noted 
that, although not included in the review due to lack of comparisons, a non-invasive technique, mini-FLOTAC, was used for detection of schistosome and other trematode infections in wildlife with promising results [92].

In addition to the comparisons included in the present study, we identified studies reporting on promising results of immunodiagnostic tests. A recent study examining thioredoxin peroxidase-1 in an ELISA system showed effective identification of $S$. japonicum in bovine hosts [78]. There are some other widely applied immunodiagnostic techniques in the field (e.g., indirect immunodiagnostic assays detecting specific schistosome induced antibody including COPT, and DDIA), which demonstrate high sensitivity but generally low specificity [26]. Circulating antigen based detection has a relatively high sensitivity, whereas the specificity becomes an issue, particularly in low transmission settings [26]. Nevertheless, it is wellrecognized that immunodiagnostic techniques face many challenges, in particular those related to cross-reactivity and identification of past infections, rather than current infections. These issues have limited, to some extent, their value as effective tools for detection of schistosome infections.

Note that only two studies pertaining to $S$. mansoni involved comparative diagnostic tests, and hence were included in the review. The Gentile et al. [90] study compared KK, ELISA, and PCR in 20 experimental rodents (Nectomys squamipes) and found that ELISA generated highest detection rate (100\%), followed by PCR (75\%) and KK (65\%). Standley et al. [73] pursued a cross-sectional survey on chimpanzees in Uganda using KK, MHT, ELISA, CCA, and qPCR and reported highest detection by ELISA (93.5\%), qPCR (54.2\%), CCA (50.0\%), KK (5.3\%), and MHT (1.1\%). However, no specific comparison across studies and tests could be made due to lack of cross-tabulated information. The overall patterns of findings are in general agreement with those on $S$. japonicum. It is worth noting that, using molecular techniques (e.g. ITS/COX-1 and PCR), some recent studies have offered important data suggesting non-human primates [93] and rodents [56] as reservoirs for S. mansoni. Although future research is needed 
to deepen the understanding of these and other potential reservoirs to human infection, these studies offer important and promising prospect for diagnosis of animal schistosome, particularly in the context of elimination of human Schistosoma transmission. Highly sensitive and accurate techniques will be the key to verification of transmission interruption.

Taking together, having reviewed and analyzed available data, we found that diagnostic techniques across the three categories exhibit substantial heterogeneities in their strengths and limitations with respect to Schistosoma diagnosis in non-human animals. The parasitologic technique, the FEA-SD and molecular techniques, especially qPCR, are potentially promising, and field-applicable techniques for schistosome diagnosis in non-human animal hosts. Future studies are needed for validation and standardization for their broader applications under realworld conditions. 


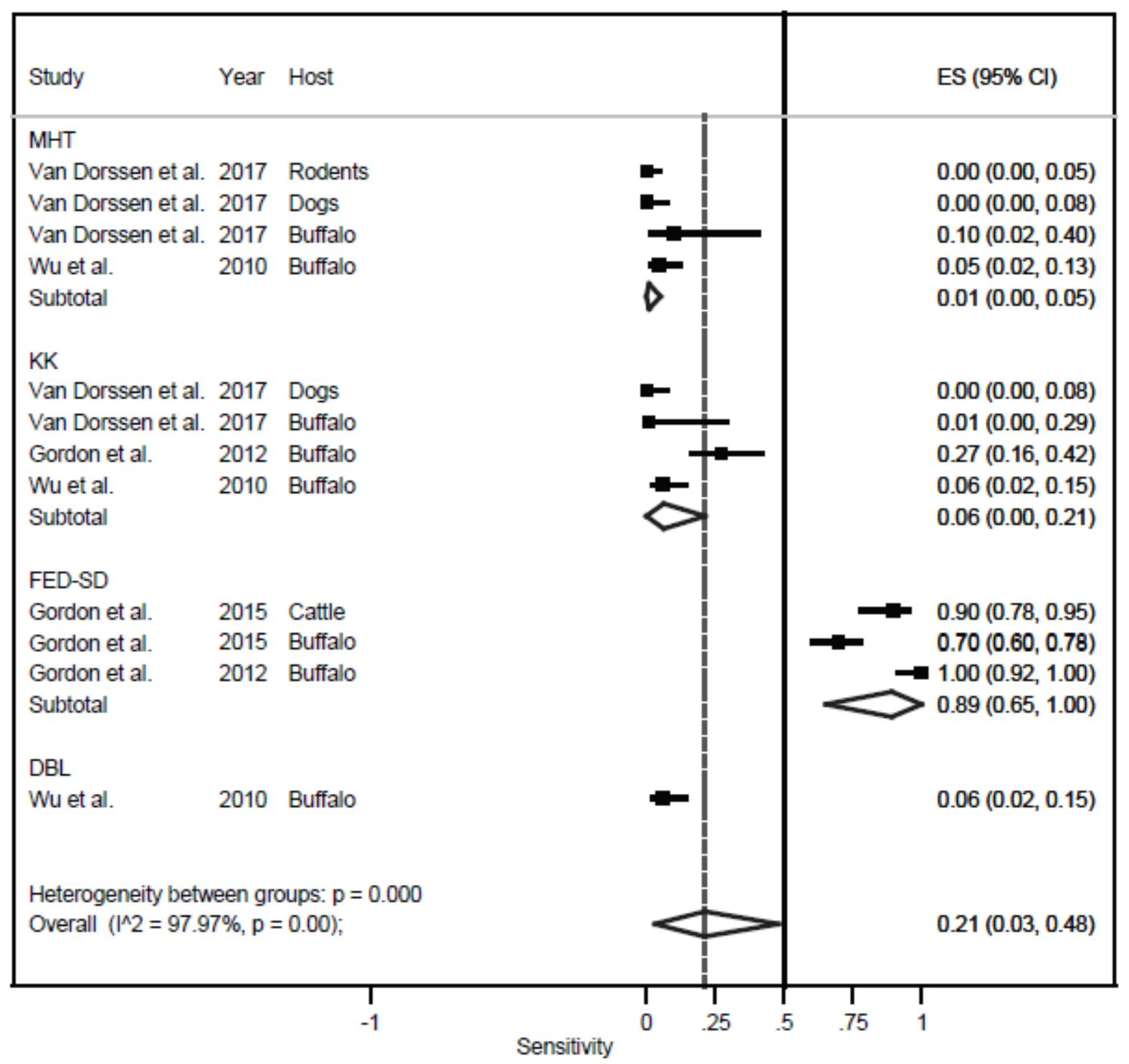

Figure 2. Meta-analysis of sensitivity of four parasitological tests (MHT, KK, DBL, and FED-SD) vs. qPCR for diagnosis of S. japonicum infection in animal hosts. Sensitivity of each parasitologic technique was estimated using $\mathrm{QPCR}$ a reference test.

\section{Acknowledgments}

This review has been commissioned and supported by the World Health Organization (WHO).

We thank the experts of the WHO schistosomiasis guideline development group for their input. 
The content for this paper is solely the responsibility of the authors and does not necessarily represent the official views of the National Institutes of Health or the World Health Organization.

\section{Funding}

SL is supported in part by the National Institutes of Health (grant number R01Al125842) and a grant from the World Health Organization. JVR was supported in part by the National Institutes of Health (grant numbers R01TW010286 and R01Al148336) and by the University of California Multicampus Research Programs and Initiatives award (MRP award \# 17-446315).

\section{References}

1. Steinmann P, Keiser J, Bos R, Tanner M, Utzinger J. Schistosomiasis and water resources development: systematic review, meta-analysis, and estimates of people at risk. Lancet Infectious Diseases. 2006;6(7):411-25. doi: Doi 10.1016/S1473-3099(06)70521-7. PubMed PMID: WOS:000238712700023.

2. Colley DG, Bustinduy AL, Secor WE, King CH. Human schistosomiasis. Lancet. 2014;383(9936):2253-64. doi: 10.1016/S0140-6736(13)61949-2. PubMed PMID: 24698483; PubMed Central PMCID: PMCPMC4672382.

3. Hotez PJ, Alvarado M, Basanez MG, Bolliger I, Bourne R, Boussinesq M, et al. The global burden of disease study 2010: interpretation and implications for the neglected tropical diseases. PLoS Negl Trop Dis. 2014;8(7):e2865. doi: 10.1371/journal.pntd.0002865. PubMed PMID: 25058013; PubMed Central PMCID: PMCPMC4109880.

4. $\quad$ Gryseels B, Polman K, Clerinx J, Kestens L. Human schistosomiasis. Lancet. 2006;368(9541):1106-18. doi: 10.1016/S0140-6736(06)69440-3. PubMed PMID: 16997665.

5. King $\mathrm{CH}$, Dickman K, Tisch DJ. Reassessment of the cost of chronic helmintic infection: a meta-analysis of disability-related outcomes in endemic schistosomiasis. Lancet. 2005;365(9470):1561-9. doi: 10.1016/S0140-6736(05)66457-4. PubMed PMID: 15866310. 6. $\quad$ McManus DP, Dunne DW, Sacko M, Utzinger J, Vennervald BJ, Zhou XN. Schistosomiasis. Nat Rev Dis Primers. 2018;4(1):13. doi: 10.1038/s41572-018-0013-8. PubMed PMID: 30093684.

7. King KC, Stelkens RB, Webster JP, Smith DF, Brockhurst MA. Hybridization in Parasites: Consequences for Adaptive Evolution, Pathogenesis, and Public Health in a Changing World. PLoS Pathog. 2015;11(9):e1005098. doi: 10.1371/journal.ppat.1005098. PubMed PMID: 26336070; PubMed Central PMCID: PMCPMC4559376.

8. Leger E, Borlase A, Fall CB, Diouf ND, Diop SD, Yasenev L, et al. Prevalence and distribution of schistosomiasis in human, livestock, and snail populations in northern Senegal: a One Health epidemiological study of a multi-host system. Lancet Planet Health. 2020;4(8):e330e42. doi: 10.1016/S2542-5196(20)30129-7. PubMed PMID: 32800151; PubMed Central PMCID: PMCPMC7443702. 
9. Leger E, Garba A, Hamidou AA, Webster BL, Pennance T, Rollinson D, et al. Introgressed Animal Schistosomes Schistosoma curassoni and S. bovis Naturally Infecting Humans. Emerg Infect Dis. 2016;22(12):2212-4. doi: 10.3201/eid2212.160644. PubMed PMID: 27869609; PubMed Central PMCID: PMCPMC5189150.

10. Leger E, Webster JP. Hybridizations within the Genus Schistosoma: implications for evolution, epidemiology and control. Parasitology. 2017;144(1):65-80. doi:

10.1017/S0031182016001190. PubMed PMID: 27572906.

11. Webster BL, Alharbi MH, Kayuni S, Makaula P, Halstead F, Christiansen R, et al. Schistosome Interactions within the Schistosoma haematobium Group, Malawi. Emerg Infect Dis. 2019;25(6):1245-7. doi: 10.3201/eid2506.190020. PubMed PMID: 31107237; PubMed Central PMCID: PMCPMC6537718.

12. Webster BL, Diaw OT, Seye MM, Webster JP, Rollinson D. Introgressive hybridization of Schistosoma haematobium group species in Senegal: species barrier break down between ruminant and human schistosomes. PLoS Negl Trop Dis. 2013;7(4):e2110. doi: 10.1371/journal.pntd.0002110. PubMed PMID: 23593513; PubMed Central PMCID: PMCPMC3617179.

13. Rollinson D, Knopp S, Levitz S, Stothard JR, Tchuem Tchuente LA, Garba A, et al. Time to set the agenda for schistosomiasis elimination. Acta Trop. 2013;128(2):423-40. doi: 10.1016/j.actatropica.2012.04.013. PubMed PMID: 22580511.

14. WHO. Schistosomiasis and soil-transmitted helminth infections. Fifty-fourth World Health Assembly, resolution WHA54.19. 2001.

15. WHO. World Health Organization. Elimination of schistosomiasis. In: SIXTY-FIFTH WORLD HEALTH ASSEMBLY. Geneva, 2012, WHA65/2012/REC/1: PP. 36-37. 2012.

16. Lai YS, Biedermann P, Ekpo UF, Garba A, Mathieu E, Midzi N, et al. Spatial distribution of schistosomiasis and treatment needs in sub-Saharan Africa: a systematic review and geostatistical analysis. Lancet Infect Dis. 2015;15(8):927-40. doi: 10.1016/S14733099(15)00066-3. PubMed PMID: 26004859.

17. Colley DG, Secor WE. A schistosomiasis research agenda. PLoS Negl Trop Dis. 2007;1(3):e32. doi: 10.1371/journal.pntd.0000032. PubMed PMID: 18060081; PubMed Central PMCID: PMCPMC2154383.

18. Ross AGP, Olveda RM, Acosta L, Ham DA, Chy D, Li YS, et al. Road to the elimination of schistosomiasis from Asia: the journey is far from over. Microbes and Infection. 2013;15(13):858-65. doi: 10.1016/j.micinf.2013.07.010. PubMed PMID: WOS:000328526200003.

19. Utzinger J, Zhou XN, Chen MG, Bergquist R. Conquering schistosomiasis in China: the long march. Acta Trop. 2005;96(2-3):69-96. PubMed PMID: 16312039.

20. Wang LD, Chen HG, Guo JG, Zeng XJ, Hong XL, Xiong JJ, et al. A strategy to control transmission of Schistosoma japonicum in China. N Engl J Med. 2009;360(2):121-8. doi: 10.1056/NEJMoa0800135. PubMed PMID: 19129526.

21. Wang LD, Guo JG, Wu XH, Chen HG, Wang TP, Zhu SP, et al. China's new strategy to block Schistosoma japonicum transmission: experiences and impact beyond schistosomiasis. Trop Med Int Health. 2009;14(12):1475-83. doi: 10.1111/j.1365-3156.2009.02403.x. PubMed PMID: 19793080.

22. Stothard JR, Stanton MC, Bustinduy AL, Sousa-Figueiredo JC, Van Dam GJ, Betson M, et al. Diagnostics for schistosomiasis in Africa and Arabia: a review of present options in control and future needs for elimination. Parasitology. 2014;141(14):1947-61. doi: 10.1017/S0031182014001152. PubMed PMID: 25158604.

23. Utzinger J, Becker SL, van Lieshout L, van Dam GJ, Knopp S. New diagnostic tools in schistosomiasis. Clinical Microbiology and Infection. 2015;21(6):529-42. doi: 10.1016/j.cmi.2015.03.014. PubMed PMID: WOS:000357553200004. 
24. Bergquist R, Johansen MV, Utzinger J. Diagnostic dilemmas in helminthology: what tools to use and when? Trends Parasitol. 2009;25(4):151-6. doi: 10.1016/j.pt.2009.01.004. PubMed PMID: 19269899.

25. Standley CJ, Mugisha L, Dobson AP, Stothard JR. Zoonotic schistosomiasis in nonhuman primates: past, present and future activities at the human-wildlife interface in Africa. Journal of Helminthology. 2012;86(2):131-40. doi: 10.1017/S0022149x12000028. PubMed PMID: WOS:000303891800001.

26. Zhou YB, Liang S, Jiang QW. Factors impacting on progress towards elimination of transmission of schistosomiasis japonica in China. Parasit Vectors. 2012;5:275. doi:

10.1186/1756-3305-5-275. PubMed PMID: 23206326; PubMed Central PMCID: PMC3519747.

27. Webster JP, Gower CM, Knowles SC, Molyneux DH, Fenton A. One health - an ecological and evolutionary framework for tackling Neglected Zoonotic Diseases. Evol Appl. 2016;9(2):313-33. doi: 10.1111/eva.12341. PubMed PMID: 26834828; PubMed Central PMCID: PMCPMC4721077.

28. Fernandez TJ, Jr., Petilla T, Banez B. An epidemiological study on Schistosoma japonicum in domestic animals in Leyte, Philippines. Southeast Asian J Trop Med Public Health. 1982;13(4):575-9. PubMed PMID: 7170639.

29. Zhou XN, Bergquist R, Leonardo L, Yang GJ, Yang K, Sudomo M, et al. Schistosomiasis japonica control and research needs. Adv Parasitol. 2010;72:145-78. doi: 10.1016/S0065308X(10)72006-6. PubMed PMID: 20624531.

30. Guo JG, Ross AG, Lin DD, Williams GM, Chen HG, Li Y, et al. A baseline study on the importance of bovines for human Schistosoma japonicum infection around Poyang Lake, China. Am J Trop Med Hyg. 2001;65(4):272-8. PubMed PMID: 11693868.

31. Gray DJ, Williams GM, Li Y, McManus DP. Transmission dynamics of Schistosoma japonicum in the lakes and marshlands of China. PLoS One. 2008;3(12):e4058. doi: 10.1371/journal.pone.0004058. PubMed PMID: 19115007; PubMed Central PMCID: PMC2605259.

32. Carlton EJ, Bates MN, Zhong B, Seto EY, Spear RC. Evaluation of mammalian and intermediate host surveillance methods for detecting schistosomiasis reemergence in southwest China. PLoS Negl Trop Dis. 2011;5(3):e987. doi: 10.1371/journal.pntd.0000987. PubMed PMID: 21408127; PubMed Central PMCID: PMCPMC3050915.

33. Guo J, Li Y, Gray D, Ning A, Hu G, Chen H, et al. A drug-based intervention study on the importance of buffaloes for human Schistosoma japonicum infection around Poyang Lake, People's Republic of China. Am J Trop Med Hyg. 2006;74(2):335-41. PubMed PMID: 16474093. 34. Wang LD. [Management of human and animal feces is a key element for effective control of epidemic of endemic schistosomiasis in China]. Zhonghua Liu Xing Bing Xue Za Zhi. 2005;26(12):929-30. PubMed PMID: 16676582.

35. Zhou YB, Liang S, Chen GX, Rea C, He ZG, Zhang ZJ, et al. An integrated strategy for transmission control of Schistosoma japonicum in a marshland area of China: findings from a five-year longitudinal survey and mathematical modeling. Am J Trop Med Hyg. 2011;85(1):83-8. doi: 10.4269/ajtmh.2011.10-0574. PubMed PMID: 21734130; PubMed Central PMCID: PMC3122349.

36. Carabin H, Balolong E, Joseph L, McGarvey ST, Johansen MV, Fernandez T, et al. Estimating sensitivity and specificity of a faecal examination method for Schistosoma japonicum infection in cats, dogs, water buffaloes, pigs, and rats in Western Samar and Sorsogon Provinces, The Philippines. Int J Parasitol. 2005;35(14):1517-24. doi: 10.1016/j.ijpara.2005.06.010. PubMed PMID: 16188261.

37. McGarvey ST, Carabin H, Balolong E, Belisle P, Fernandez T, Joseph L, et al. Crosssectional associations between intensity of animal and human infection with Schistosoma japonicum in Western Samar province, Philippines. Bulletin of the World Health Organization. 2006;84(6):446-52. doi: Doi 10.2471/Blt.05.026427. PubMed PMID: WOS:000238304900012. 
38. Olveda RM, Tallo V, Olveda DU, Inobaya MT, Chau TN, Ross AG. National survey data for zoonotic schistosomiasis in the Philippines grossly underestimates the true burden of disease within endemic zones: implications for future control. International Journal of Infectious Diseases. 2016;45:13-7. doi: 10.1016/j.ijid.2016.01.011. PubMed PMID: WOS:000374877300003.

39. Rudge JW, Carabin H, Balolong E, Tallo V, Shrivastava J, Lu DB, et al. Population genetics of Schistosoma japonicum within the Philippines suggest high levels of transmission between humans and dogs. PLoS Negl Trop Dis. 2008;2(11):e340. doi: 10.1371/journal.pntd.0000340. PubMed PMID: 19030225; PubMed Central PMCID: PMCPMC2582952.

40. Lu DB, Rudge JW, Wang TP, Donnelly CA, Fang GR, Webster JP. Transmission of Schistosoma japonicum in marshland and hilly regions of China: parasite population genetic and sibship structure. PLoS Negl Trop Dis. 2010;4(8):e781. doi: 10.1371/journal.pntd.0000781. PubMed PMID: 20689829; PubMed Central PMCID: PMCPMC2914789.

41. Lu DB, Wang TP, Rudge JW, Donnelly CA, Fang GR, Webster JP. Evolution in a multihost parasite: chronobiological circadian rhythm and population genetics of Schistosoma japonicum cercariae indicates contrasting definitive host reservoirs by habitat. Int J Parasitol. 2009;39(14):1581-8. doi: 10.1016/j.jpara.2009.06.003. PubMed PMID: 19577571.

42. Lu DB, Wang TP, Rudge JW, Donnelly CA, Fang GR, Webster JP. Contrasting reservoirs for Schistosoma japonicum between marshland and hilly regions in Anhui, China--a two-year longitudinal parasitological survey. Parasitology. 2010;137(1):99-110. doi: 10.1017/S003118200999103X. PubMed PMID: 19723358.

43. Rudge JW, Lu DB, Fang GR, Wang TP, Basanez MG, Webster JP. Parasite genetic differentiation by habitat type and host species: molecular epidemiology of Schistosoma japonicum in hilly and marshland areas of Anhui Province, China. Mol Ecol. 2009;18(10):213447. doi: 10.1111/j.1365-294X.2009.04181.x. PubMed PMID: 19389178.

44. Wang TP, Vang Johansen M, Zhang SQ, Wang FF, Wu WD, Zhang GH, et al. Transmission of Schistosoma japonicum by humans and domestic animals in the Yangtze River valley, Anhui province, China. Acta Trop. 2005;96(2-3):198-204. doi:

10.1016/j.actatropica.2005.07.017. PubMed PMID: 16188215.

45. Van Dorssen CF, Gordon CA, Li Y, Williams GM, Wang Y, Luo Z, et al. Rodents, goats and dogs - their potential roles in the transmission of schistosomiasis in China. Parasitology. 2017:1633-42. doi: 10.1017/S0031182017000907.

46. Rudge JW, Webster JP, Lu DB, Wang TP, Fang GR, Basanez MG. Identifying host species driving transmission of schistosomiasis japonica, a multihost parasite system, in China. Proc Natl Acad Sci U S A. 2013;110(28):11457-62. doi: 10.1073/pnas.1221509110. PubMed PMID: 23798418; PubMed Central PMCID: PMCPMC3710859.

47. Liang S, Yang C, Zhong B, Qiu D. Re-emerging schistosomiasis in hilly and mountainous areas of Sichuan, China. Bull World Health Organ. 2006;84(2):139-44. doi: /S0042-96862006000200015. PubMed PMID: 16501732; PubMed Central PMCID: PMCPMC2626530.

48. Carabin H, McGarvey ST, Sahlu I, Tarafder MR, Joseph L, De Andrade BB, et al. Schistosoma japonicum in Samar, the Philippines: infection in dogs and rats as a possible risk factor for human infection. Epidemiology and Infection. 2015;143(8):1767-76. doi:

10.1017/S0950268814002581. PubMed PMID: WOS:000354061100025.

49. Kamiya H, Tada Y, Matsuda H, Tanaka H, Blas BL, Nosenas JS, et al. Annual fluctuation of Schistosoma japonicum infection in field rats, Rattus rattus mindanensis, in Dagami, Leyte, Philippines. Jpn J Exp Med. 1980;50(5):375-82. PubMed PMID: 7206265. 50. Gordon CA, Acosta LP, Gray DJ, Olveda RM, Jarilla B, Gobert GN, et al. High prevalence of Schistosoma japonicum infection in Carabao from Samar Province, the Philippines: implications for transmission and control. PLoS Negl Trop Dis. 2012;6(9):e1778. doi: 
10.1371/journal.pntd.0001778. PubMed PMID: 23029571; PubMed Central PMCID: PMCPMC3447974.

51. Duplantier JM, Sene M. Rodents as reservoir hosts in the transmission of Schistosoma mansoni in Richard-Toll, Senegal, West Africa. Journal of Helminthology. 2000;74(2):129-35. PubMed PMID: WOS:000087729200005.

52. Ghandour AM, Zahid NZ, Banaja AA, Kamal KB, Bouq Al. Zoonotic intestinal parasites of hamadryas baboons Papio hamadryas in the western and northern regions of Saudi Arabia. Journal of Tropical Medicine and Hygiene. 1995;98(6):431-9. PubMed PMID: WOS:A1995TP97500012.

53. Giboda M, Ditrich O, Sterba. Schistosoma-Margrebowiei Human Patent Zoonotic Schistosomiasis Imported from Zambia. Bulletin De La Societe De Pathologie Exotique. 1988;81(4):749-51. PubMed PMID: WOS:A1988R667100015.

54. Taylor MG, Nelson GS, Andrews BJ. Case of Natural Infection of S-Haematobium in a Senegalese Baboon (Papio-Sp). Transactions of the Royal Society of Tropical Medicine and Hygiene. 1972;66(1):16-\&. doi: Doi 10.1016/0035-9203(72)90028-4. PubMed PMID: WOS:A1972L772900028.

55. Catalano S, Ba K, Diouf ND, Leger E, Verocai GG, Webster JP. Rodents of Senegal and their role as intermediate hosts of Hydatigera spp. (Cestoda: Taeniidae). Parasitology. 2019;146(3):299-304. doi: 10.1017/S0031182018001427. PubMed PMID: 30152308. 56. Catalano S, Sene M, Diouf ND, Fall CB, Borlase A, Leger E, et al. Rodents as Natural Hosts of Zoonotic Schistosoma Species and Hybrids: An Epidemiological and Evolutionary Perspective From West Africa. J Infect Dis. 2018;218(3):429-33. doi: 10.1093/infdis/jiy029. PubMed PMID: 29365139.

57. Muller-Graf CD, Collins DA, Packer C, Woolhouse ME. Schistosoma mansoni infection in a natural population of olive baboons (Papio cynocephalus anubis) in Gombe Stream National Park, Tanzania. Parasitology. 1997;115 ( Pt 6):621-7. PubMed PMID: 9488873. 58. Catalano S, Leger E, Fall CB, Borlase A, Diop SD, Berger D, et al. Multihost Transmission of Schistosoma mansoni in Senegal, 2015-2018. Emerg Infect Dis. 2020;26(6):1234-42. doi: 10.3201/eid2606.200107. PubMed PMID: 32441625; PubMed Central PMCID: PMCPMC7258455.

59. Legesse M, Erko B. Zoonotic intestinal parasites in Papio anubis (baboon) and Cercopithecus aethiops (vervet) from four localities in Ethiopia. Acta Tropica. 2004;90(3):231-6. doi: 10.1016/j.actatropica.2003.12.003. PubMed PMID: WOS:000221281100001.

60. Webster JP, Borlase A, Rudge JW. Who acquires infection from whom and how? Disentangling multi-host and multi-mode transmission dynamics in the 'elimination' era. Philos Trans R Soc Lond B Biol Sci. 2017;372(1719). doi: 10.1098/rstb.2016.0091. PubMed PMID: 28289259; PubMed Central PMCID: PMCPMC5352818.

61. Moher D, Liberati A, Tetzlaff J, Altman DG, Grp P. Preferred Reporting Items for Systematic Reviews and Meta-Analyses: The PRISMA Statement. Plos Medicine. 2009;6(7). doi: ARTN e1000097

10.1371/journal.pmed.1000097. PubMed PMID: WOS:000268452400005.

62. Cohen J. A coefficient of agreement for nominal scales. Educational and Psychological Measurement 1960;XX(1):37-46.

63. Fung MS, Xiao N, Wang S, Carlton EJ. Field Evaluation of a PCR Test for Schistosoma japonicum Egg Detection in Low-Prevalence Regions of China. Am J Trop Med Hyg. 2012;87:1053-8. doi: 10.4269/ajtmh.2012.12-0177.

64. Oliveira LMA, Santos HLC, Goncalves MML, Barreto MGM, Peralta JM. Evaluation of polymerase chain reaction as an additional tool for the diagnosis of low-intensity Schistosoma mansoni infection. Diagn Micr Infec Dis. 2010;68(4):416-21. doi:

10.1016/j.diagmicrobio.2010.07.016. PubMed PMID: WOS:000285031700012. 
65. Schols R, Carolus H, Hammoud C, Mulero S, Mudavanhu A, Huyse T. A rapid diagnostic multiplex PCR approach for xenomonitoring of human and animal schistosomiasis in a 'One Health' context. Trans R Soc Trop Med Hyg. 2019;113(11):722-9. doi: 10.1093/trstmh/trz067. PubMed PMID: 31369105.

66. Wu HW, Qin YF, Chu K, Meng R, Liu Y, McGarvey ST, et al. High prevalence of Schistosoma japonicum infection in water buffaloes in the Philippines assessed by real-time polymerase chain reaction. Am J Trop Med Hyg. 2010;82(4):646-52. doi: 10.4269/ajtmh.2010.09-0638. PubMed PMID: 20348514; PubMed Central PMCID: PMCPMC2844580.

67. Nyaga VN, Arbyn M, Aerts M. Metaprop: a Stata command to perform meta-analysis of binomial data. Archives of Public Health. 2014;72:39. doi: 10.1186/2049-3258-72-39.

68. Jiang W-M, Xiang J, Jiang X-M, Li N, Xiao G-M. Comparative study on detection of Schistosoma japonicum by Triple-dot ELISA and stool assay. Shanghai Journal of Animal Husbandry and Veterinary Medicine. 2006;3:21-2.

69. Lu F-Z, Fang L-Y, Zhang X-J, Liu E-Y, Mao G-Q, Zhu J-X, et al. Study on Two-step Dot Immunogold Filtration Assay for Detecting Anti-Schistosome Antibodies in Livestock. Acta Veterinaria et Zootechnica Sinica. 2006;37:687-92.

70. Peng Y-C, Deng Z-F, Ouyang X-X, Shi Y-J, Tan S-G, Shen P. Application of rapid colloidal gold immunochromatography assay strip for detection of domestic animal's Schistosomiasis in endemic areas. Chinese Journal of Animal Infectious Diseases. 2009;17:6770.

71. Sun $\mathrm{XH}$, Zhang DA. Report of rapid diagnosis of schistosomiasis by PAPS immuno microspheres. Hubei Journal of Animal and Veterinary Sciences. 1992.

72. Gordon CA, Acosta LP, Gobert GN, Jiz M, Olveda RM, Ross AG, et al. High prevalence of Schistosoma japonicum and Fasciola gigantica in bovines from Northern Samar, the Philippines. PLoS Negl Trop Dis. 2015;9(2):e0003108. doi: 10.1371/journal.pntd.0003108. PubMed PMID: 25643317; PubMed Central PMCID: PMCPMC4313937.

73. Standley CJ, Mugisha L, Verweij JJ, Adriko M, Arinaitwe M, Rowell C, et al. Confirmed Infection with Intestinal Schistosomiasis in Semi-Captive Wild-Born Chimpanzees on Ngamba Island, Uganda. Vector Borne Zoonotic Dis. 2011;11:169-76. doi: 10.1089/vbz.2010.0156. 74. Katz N, Chaves A, Pellegrino J. A simple device for quantitative stool thick-smear technique in Schistosomiasis mansoni. Rev Inst Med Trop Sao Paulo. 1972;14(6):397-400. PubMed PMID: 4675644.

75. Yu JM, de Vlas SJ, Jiang QW, Gryseels B. Comparison of the Kato-Katz technique, hatching test and indirect hemagglutination assay (IHA) for the diagnosis of Schistosoma japonicum infection in China. Parasitol Int. 2007;56(1):45-9. doi: 10.1016/j.parint.2006.11.002. PubMed PMID: 17188018.

76. Willingham AL, Johansen MV, Barnes EH. A new technique for counting Schistosoma japonicum eggs in pig feces. Southeast Asian J Trop Med Public Health. 1998;29:128-30.

77. Xu B, Gordon CA, Hu W, McManus DP, Chen HG, Gray DJ, et al. A novel procedure for precise quantification of Schistosoma japonicum eggs in bovine feces. PLoS Negl Trop Dis. 2012;6(11):e1885. doi: 10.1371/journal.pntd.0001885. PubMed PMID: 23166847; PubMed Central PMCID: PMC3499414.

78. Angeles JMM, Goto Y, Kirinoki M, Asada M, Leonardo LR, Rivera PT, et al. Utilization of ELISA Using Thioredoxin Peroxidase-1 and Tandem Repeat Proteins for Diagnosis of Schistosoma japonicum Infection among Water Buffaloes. Plos Neglected Tropical Diseases. 2012;6(8). doi: ARTN e1800

10.1371/journal.pntd.0001800. PubMed PMID: WOS:000308497100035. 
79. Peng YC, Zhang DJ, Shi YJ, Li H, Lu K, Liu JM, et al. Comparison among three antigens for the diagnosis of schistosomiasis japonicum in domestic animals. Veterinary Science in China. 2006;36:207-11.

80. Wang LX, Zhao JH, He L, Liu Q, Zhou DN, Zhou YQ, et al. An indirect ELISA for detection of Theileria sergenti antibodies in water buffalo using a recombinant major piroplasm surface protein. Veterinary Parasitology. 2010;170:323-6. doi: 10.1016/j.vetpar.2010.02.009.

81. Xu R, Feng J, Hong Y, Lv C, Zhao D, Lin J, et al. A novel colloidal gold immunochromatography assay strip for the diagnosis of schistosomiasis japonica in domestic animals. Infectious Diseases of Poverty. 2017;6. doi: 10.1186/s40249-017-0297-z.

82. Zhang X-j, Lu F-z, Liu E-y, Fang L-y, Yang A-g, He Y-q, et al. Study on sensitivity and specificity of Dot Immunogold Filtration Assay for detecting circulating anti-schistosome antibodies of livestock. Acta Agriculturae Zhejiangensis. 2006;18:453-7.

83. Van Gool T, Vetter H, Vervoort T, Doenhoff MJ, Wetsteyn J, Overbosch D.

Serodiagnosis of imported schistosomiasis by a combination of a commercial indirect hemagglutination test with Schistosoma mansoni adult worm antigens and an enzyme-linked immunosorbent assay with S. mansoni egg antigens. J Clin Microbiol. 2002;40(9):3432-7. PubMed PMID: 12202589; PubMed Central PMCID: PMC130766.

84. Hillyer GV, Ramzy RM, El Alamy MA, Cline BL. The circumoval precipitin test for the serodiagnosis of human schistosomiasis mansoni and haematobia. Am J Trop Med Hyg. 1981;30(1):121-6. PubMed PMID: 7212158.

85. Garcia EG, Tapales FP, Valdez CA, Mitchell GF, Tiu WU. Attempts to standardize the circumoval precipitin test (copt) for Schistosomiasis japonica. Southeast Asian J Trop Med Public Health. 1981;12(3):384-95. PubMed PMID: 7342326.

86. Zhu YC. Immunodiagnosis and its role in schistosomiasis control in China: a review. Acta Trop. 2005;96(2-3):130-6. doi: 10.1016/j.actatropica.2005.07.007. PubMed PMID: 16143288.

87. He W, Zhu Y-C, Xu M, Cao G-Q, Hua W-Q, Ye P. Development of rapid immunodiagnosis assay for domestic animal schistosomiasis with colloidal dye dipstick immunoassay( DDIA). Chinese Journal of Veterinary Parasitology. 2002;10.

88. Wen LY, Chen JH, Ding JZ, Zhang JF, Lu SH, Yu LL, et al. Evaluation on the applied value of the dot immunogold filtration assay (DIGFA) for rapid detection of anti-Schistosoma japonicum antibody. Acta Trop. 2005;96(2-3):142-7. doi: 10.1016/j.actatropica.2005.07.025. PubMed PMID: 16207482.

89. Xu ZM, Liu JW, Xu H, Huang HS, Rao XM, Xiong ZL. Application of rapid diagnosis of schistosomiasis in livestock by PAPS immune microsphere method. Jiangxi Agricultural Science \& Technology. 1998:11-2.

90. Gentile R, Maria M, Gonç Alves L, Fraga S, Neto DC, Matos Da Costa M, et al. Evaluation of immunological, parasitological and molecular methods for the diagnosis of Schistosoma mansoni infection before and after chemotherapy treatment with praziquantel in experimentally infected Nectomys squamipes. Veterinary Parasitology. 2011;180:243-9. doi: 10.1016/j.vetpar.2011.03.007.

91. Zhang X-j, Wang Y-c, Huang X-z, Yang J-Z, Jin M-I, Liu T-j, et al. Study on spot enzyme - linked immunosorbent assay in diagnosis of animal schistosomiasis. Chinese Journal of Veterinary Technology. 1993;23:9-11. doi: : 10. 16656 /j . i ssn. 1673 -4696. 1993. 06.004. 92. Catalano S, Symeou A, Marsh KJ, Borlase A, Leger E, Fall CB, et al. Mini-FLOTAC as an alternative, non-invasive diagnostic tool for Schistosoma mansoni and other trematode infections in wildlife reservoirs. Parasit Vectors. 2019;12(1):439. doi: 10.1186/s13071-019-36136. PubMed PMID: 31522684; PubMed Central PMCID: PMCPMC6745783.

93. Kebede T, Bech N, Allienne JF, Olivier R, Erko B, Boissier J. Genetic evidence for the role of non-human primates as reservoir hosts for human schistosomiasis. PLoS Negl Trop Dis. 
2020;14(9):e0008538. doi: 10.1371/journal.pntd.0008538. PubMed PMID: 32898147; PubMed Central PMCID: PMCPMC7500647. 